
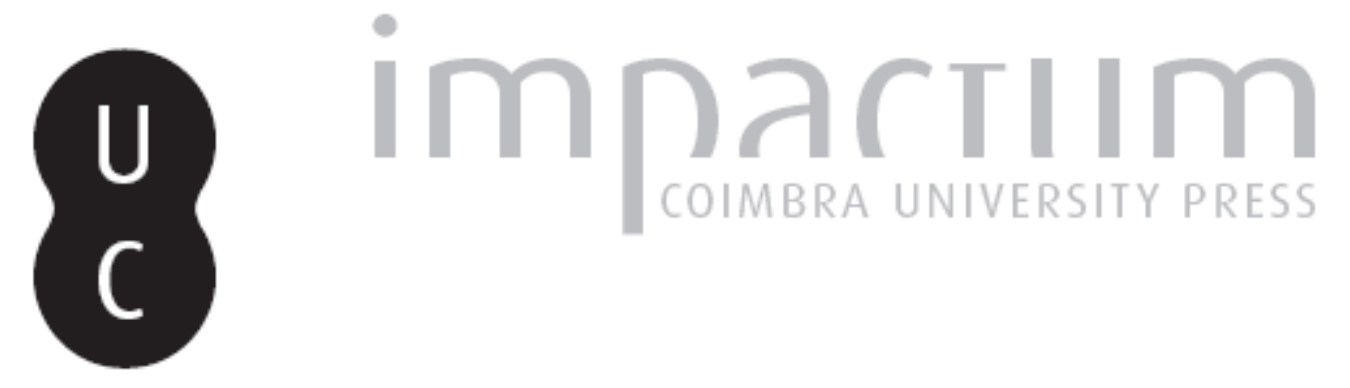

\title{
[Recensão a] Enrique Martínez Ruiz, La Delincuencia Contemporanea. Introducción a la delincuencia isabelina
}

\author{
Autor(es): $\quad$ Roque, João Gouveia \\ Publicado por: Imprensa da Universidade de Coimbra \\ URL \\ persistente: \\ URI:http://hdl.handle.net/10316.2/43845 \\ DOI: \\ DOI:https://doi.org/10.14195/2183-8925_6_17
}

Accessed : $\quad$ 26-Apr-2023 11:26:03

A navegação consulta e descarregamento dos títulos inseridos nas Bibliotecas Digitais UC Digitalis, UC Pombalina e UC Impactum, pressupõem a aceitação plena e sem reservas dos Termos e Condições de Uso destas Bibliotecas Digitais, disponíveis em https://digitalis.uc.pt/pt-pt/termos.

Conforme exposto nos referidos Termos e Condições de Uso, o descarregamento de títulos de acesso restrito requer uma licença válida de autorização devendo o utilizador aceder ao(s) documento(s) a partir de um endereço de IP da instituição detentora da supramencionada licença.

Ao utilizador é apenas permitido o descarregamento para uso pessoal, pelo que o emprego do(s) título(s) descarregado(s) para outro fim, designadamente comercial, carece de autorização do respetivo autor ou editor da obra.

Na medida em que todas as obras da UC Digitalis se encontram protegidas pelo Código do Direito de Autor e Direitos Conexos e demais legislação aplicável, toda a cópia, parcial ou total, deste documento, nos casos em que é legalmente admitida, deverá conter ou fazer-se acompanhar por este aviso.

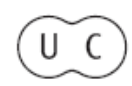




\section{REVISTA DE HISTORIA DAS IDEIAS 6}

\section{. \\ REVOLTAS E REVOLUCOEES}

*

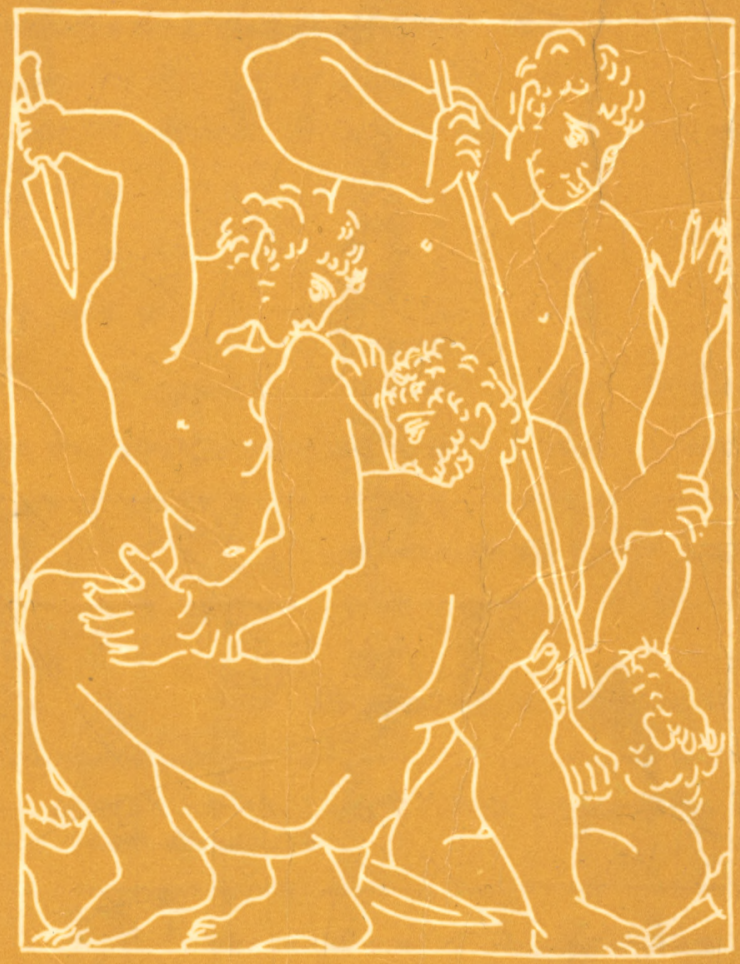

INSTITUTO DE HISTORIA E TEORIA DAS IDEIAS FACULDADE DE LETRAS 
Tombo. Quanto a nós, divididos por outros interesses e por outras tarefas de investigação, tentaremos ao menos publicar o processo exemplar de Manuel Fernandes Vila Real, que há já bastante tempo vimos a prometer e cuja leitura, levada a efeito pelas bibliotecárias-arquivistas Ângela Gama e Ana Maria Osório, está em fase de grande adiantamento. Mas impõe-se sobretudo um trabalho sistemático, feito por equipas de investigadores. Tal como as tentativas que estão a ser feitas nesse sentido no Brasil, para o caso dos cristãos-novos, por uma equipa dirigida pela professora da Universidade de São Paulo, Anita Novinsky. Oxalá que um trabalho, projectado pelo Núcleo de Sociologia Histórica do Instituto Gulbenkian de Ciência e orientado por Robert Rowland, de tratamento informático de dados extraídos dos arquivos do Santo Ofício possa ser levado a bom termo, pois será um primeiro caminho para essa pesquisa sistemática.

Para finalizar estas reflexões tecidas à volta do livro publicado por Raúl Rego, uma palavra de louvor é devida à Biblioteca Nacional de Lisboa, que tem prosseguido na importante tarefa de dar à luz documentos inéditos ou de reeditar obras esquecidas ou dispersas. E essa iniciativa é de valorizar ainda porque uma instituição com o seu prestígio não se tem limitado à edição erudita e académica, consciente de que a divulgação séria faz parte importante das suas atribuições. As suas sugestivas e constantes exposições e mostras documentais e bibliográficas são também uma prova dessa vivacidade. Uma biblioteca não é um depósito de livros - é uma instituição de cultura viva e actuante.

Luís Reis Torgal

Enrique Martínez Ruiz, La Delincuencia Contemporanea. Introducción a la delincuencia isabelina, Universidad de Granada, 1982. 276+13 in. pp. (Prólogo de Vicente Palacio Atard).

De Espanha nos chegou o título que ilustra, segundo pensamos, a variedade e a importância da recente historiografia espanhola e a sua abertura (à semelhança das de outros países) às «novas» correntes, interpretações e temáticas no domínio da história.

$\mathrm{Na}$ esteira da "escola» dos Annales e de outros contributos, desde há décadas que se vêm afirmando novas concepções, arroteando novos terrenos e desenhando mais am- 


\section{Recensões}

plos horizontes no âmbito das ciências humanas ou sociais, caso da história.

No que a esta concerne, emergiu e consolidou-se a «história social", em sentido lato. "Privilegiando" o estudo da sociedade e dos homens, numa perspectiva "totalizante». Dissociando e articulando "revoluções» e "quase imobilidades» no tempo e no espaço. Quantificando e descrevendo. Operando com números e "fontes qualitativas". Preocupando-se com os indivíduos e com os grupos, numa relação de equilíbrio/desequilíbrio. Relacionando homens e coisas, objectos e ideias. Distinguindo e recompondo níveis. Subindo e/ou descendo do económico, ao social e ao mental.

$\mathrm{Na}$ diversificação e "unificação» assim realizadas ou perseguidas nenhum sector e nenhuma franja das realidades (ou imagens) sociais se querem omitidos ou subalternizados. Daí que a "marginalidade» e a delinquência (expressão ou cruzamento de tensões, conflitos e motivações de variada ordem; revelação ou disfarce de comportamentos comuns ou "autónomos»; diálogo e/ou confronto de normalidades e anomalias) tenham vindo a suscitar, também elas, o interesse dos estudiosos e investigadores em muitos países, com assinalado destaque (julgamos) para a historiografia francesa (de que poderíamos aqui apontar diversos exemplos).

Quiçá esse interesse (como outros) resulte, em parte, dos condicionamentos típicos da nossa contemporaneidade (e pode ser de outro modo?). Marcada por uma sensibilidade, difusa e impulsiva, às graves questões da criminalidade e, mais latamente, aos problemas de segurança. Quiçá esse interesse represente (ou corra o risco de significar) uma espécie de «moda». Mas, face aos resultados científicos já obtidos e às lacunas a preencher, este novo "objecto e desafio" da história merece reconhecimento e continuidade.

Particularmente válida e estimulante é a contribuição do livro de Enrique Martínez Ruiz que aqui tentaremos sumariamente «inventariar» e comentar, numa simples e despretensiosa «nota de leitura».

O Autor é um conceituado estudioso (nomeadamente dọs problemas de segurança pública no século XIX) e docente universitário espanhol, na Universidade de Granada, primeiro, e, actualmente, na de Madrid (Complutense).

$\mathrm{Na}$ presente obra, inserida na linha das suas investigações, pretende aproximar-se e aproximar-nos da delinquência no reinado da filha de Fernando VII, Isabel II. Em lugar das manifestações espectaculares, acidentais e episódicas e das vertentes políticas da ordem pública e seus problemas, Martínez Ruiz aborda, propositadamente, as dimensões in- 
ternas e as facetas menos conhecidas, mais correntes e comuns (íamos a escrever mais profundas e "normais») da delinquência.

Compõem o livro, além da Introducción, os seguintes "capítulos» - La España Isabelina: Bases y Conflictividad; Factores incidentes en la Delincuencia; Las Fuentes; Trayectoria de la delincuencia isabelina: Aproximación a su evolución y cuantía; Intensidad provincial de la Delincuencia; Análisis regional de la Delincuencia; Los delincuentes; Delitos y Penas. Inclui, no final, uma série de Apêndices, com um variado e rico conjunto de elementos estatísticos.

Genericamente (e simplificando), poderemos distinguir, como "partes" essenciais no corpo da obra e no fulcro das atenções do seu autor, as questões seguintes: explicação sociológica (ou socio-económica, infra-estrutural) das linhas e forças da "conflictividad» e da delinquência (derivada daquela); evolução e ritmos da delinquência e suas variações regionais; caracterização dos delinquentes e apreciação dos delitos e penas.

No que se refere aos condicionalismos influentes, directa ou indirectamente (e numa dualidade de sentidos), na delinquência consideram-se:

a) $\mathrm{O}$ crescimento demográfico (Um crescimento, mesclado de "modernidade» e de antigo regime, gerador de pressões e sem correspondência plena no desenvolvimento económico).

b) As limitações e bloqueios do quadro agrícola ( Una Agricultura sin Alicientes»).

c) A dissolução dos senhorios (Tendo em conta, designadamente, as tensões, reservas e frustrações do processo abolicionista).

d) A desamortização (Com benefício especial de determinados grupos e consequente frustração das esperanças de milhares de trabalhadores aspirantes à posse de uma parcela de terra em propriedade).

Após a análise da agricultura espanhola e das suas questões fundamentais, nas alíneas antecedentes, a consideração de outros tópicos:

e) O estado embrionário da indústria (Daí decorrendo que "la industria no era una alternativa válida para la agricultura; no había alcanzado aún el desarrollo necessario para crear, mediante una amplia oferta de trabajo, polos de atracción demográfica que aliviara la presión agraria. La conflictividad, con ello, no hubiera disminuido, pero se hubiera diversificado y su reflexo en la delincuencia hubiera sido inevitable» - p. 62). 
f) As insuficiências das comunicações e a desarticulação do mercado nacional (Não contribuindo assim para "disminuir la conflictividad de las regiones españolas, que siguieron sometidas a las presiones propias de cada una, afectadas por una delincuencia, cuyo carácter provincial es una de sus peculiaridades distintivas»-p. 64; sem que a construção de estradas e sua manutenção e nem mesmo o caminho de ferro hajam concorrido, nomeadamente pela via da oferta de trabalho, de modo significativo e regular para a superação de conflitos).

Analisam-se, em suma, na série de tópicos referidos o panorama material (revelador duma Espanha essencialmente agrária e com um grau de desenvolvimento social e econó. mico algo atrasado) e seus reflexos potenciais na delinquência e sua natureza (uma delinquência eminentemente agrária). Análise essa em que os diversos factores ponderados são simultaneamente isolados e integrados numa perspectiva de interrelacionamento e de conjunto.

Servindo-se de fontes específicas (que critica), utilizando as relações (incompletas) de capturas verificadas $\mathrm{e}$ publicadas pela "Guardia Civil», Martínez Ruiz traça-nos, de seguida, a "trajectória" da delinquência (repartida por vários gráficos), no período de 1846-1867. Além da análise dos dados globais, aprecia e comenta as diferentes colunas ou figuras delituosas incluídas: detenções por "faltas leves" (o maior número), "contrabandos» (de que prescinde, por razões que explica), "desertores», "prófugos», "delincuentes» e "ladrones».

De imediato, ocupa-se o Autor das questões da «intensidad provincial» (com recurso a representação gráfica, em mapas) e da "análise regional» da delinquência, relacionando determinados elementos e coordenadas.

Após tal descida aos níveis provinciais e regionais de avaliação do delito, "entra-se» no mundo dos delinquentes, cuja "caracterização" se ensaia a partir de dados fornecidos pelos Anuarios Estadísticos relativos apenas aos anos de 1859 a 1862 (escolha esta determinada pela uniformidade dos respectivos quadros e pela "normalidade» desses anos).

Confrontam-se os números de processados e condenados ("penados») - um pouco menos de metade daqueles.

Repartem-se estes segundo os conceitos de «autores» (a grande maioria dos sentenciados, à volta de $97 \%$ ), "cómplices» e "encubridores", com distinção complementar por sexos - permitindo "concluir que en la perpetración material de los delitos, las mujeres suponen un número que oscila en torno a la séptima parte del de hombres, proporción que 
aumenta a una sexta parte, aproximadamente, en los cómplices y se incrementa sensiblemente en los encubridores, donde alcanzan cifras similares a las de los varones, dato significativo y explicable, por cuanto el cómplice es el menos favorecido de los posibles beneficiarios de la perpetración de un delito, lo que hace este papel poco 'rentable' para un hombre que accederá a ello, tal vez, coaccionado, mientras que la mujer puede verse empujada a ser encubridora por una gama más variada de razones, especialmente, por el parentesco. En los porcentajes totales, los hombres se mueven entre el 86 y el $88 \%$ y las mujeres se situan en torno al 12 y el $13 \%$ - (p. 159).

Assinala-se a pequena importância da "reincidência». Classificam-se os "penados» por grupos de idades (evidenciando determinadas cifras a primazia de pessoas jovens); distingue-se entre comportamento feminino e masculino, avança-se com explicações sectoriais.

Apreciam-se os valores relativos à "naturaleza» e "vecindad" dos condenados, manifestando muito claramente a proximidade entre domicílio e local do crime ( rrealidad que nos hace pensar que los delincuentes encontrarían un grado de impunidad aceptable para actuar en su propia provincia, donde tendrían más ou menos organizada su vida, resultándole más seguro actuar en un ambiente conocido que cambiar de domicilio o enfrentarse a un medio hostil. A parte de que el desarrollo de las comunicaciones era muy mediocre y el ferrocarril, todavía en embrión, no había 'empeque. ñecido' las distancias»-p. 164).

Regista-se a classificação dos "penados» segundo o estado civil (cabendo aos solteiros o número maioritário) e, no caso dos casados e viúvos, distingue-se ainda quanto a terem ou não filhos. Sublinham-se as variações de representatividade entre grupos e sexos.

Analisam-se o nível de instrução (evidenciando-se a larga maioria de analfabetos e a desigualdade das mulheres) e a repartição profissional (constituindo os jornaleiros o contıngente maioritário).

Assim visualizado e questionado (mediante imagens e reflexões múltiplas) o mundo dos delinquentes, Martínez Ruiz aborda, por último, o assunto dos delitos e penas. Entre outros dados e linhas de reflexão, consideram-se: o grau de desenvolvimento dos delitos ("consumados», "frustrados», "tentativas", "conspiración para delinquir", "proposición para delinquir»); as suas motivações - «causas impulsivas» ("codicia», "miseria», "odio o venganza», "riña», "mala educación", «embriaguez», «lujuria», "amor o celos», "disensiones 
políticas», «otros motivos»); os dias em que se cometem (sendo superior ao dos dias em que se pode trabalhar o índice de delinquência dos dias festivos); os objectos utilizados nos crimes de violência contra as pessoas; a tipificação do delito; as penas impostas ("penas correccionales»- as predominantes - "penas aflictivas», "penas leves», "penas comunes"; em todos estes quadros, com a respectiva distribuição interna).

Julgamos que o esboço que delineámos, apesar de grosseiro e fragmentado, poderá contribuir, de algum modo, para suscitar o interesse dos leitores e universitários portugueses por esta "Introducción a la delincuencia isabelina» do Prof. Enrique Martínez Ruiz.

Obra importante e sugestiva a diversos níveis. Pela sua relativa "novidade» (no panorama historiográfico espanhol). Pelo seu carácter unitário e multifacetado. Pela variedade e riqueza dos dados (embora, naturalmente, incompletos). Pela sua atenção ao geral e ao regional. Pelas hipóteses ou conclusões avançadas. Pela "sensibilidade» do Autor às limitações, às dificuldades, aos matizes, à "subjectividade» que semelhante temática sempre envolve.

Obra que vale por ela. E não menos valerá pelos novos trabalhos e aprofundamentos que sugerir, enquanto "ponto de partida".

Embora, muito provavelmente, com alguma impropriedade crítica, não queremos deixar, por outro lado, de anotar alguns dos reparos ou "reservas» que o livro nos deixou. Pensamos que seria conveniente que a bibliografia (citada nas "notas» aos diversos "capítulos») figurasse numa lista final. Parece-nos existir uma sobrevalorização dos factores socio-económicos. Justificar-se-ia, se possível, que, paralelamente com a análise dos delinquentes, se penetrasse no "território» das "vítimas». Somos de opinião que se impunha algum confronto com outros estudos (de diferentes espaços e origens).

Longa vai já a "nota de leitura» que gostosamente redigimos. Terminemo-la com um desejo e uma confissão: que se multipliquem por muitos leitores o proveito e o privilégio que fruímos com tal leitura. E porque não ainda com um "apelo»: aos estudiosos de ambos os países (Portugal e Espanha) para que, reciprocamente, se incremente e diversifique a divulgação dos seus trabalhos - no interesse do público, da ciência e da cultura.

João Lourenço Roque 